\title{
Effect of the herbal mixture composed of Aloe Vera, Henna, Adiantum capillus-veneris, and Myrrha on wound healing in streptozotocin-induced diabetic rats
}

\author{
Hamid Galehdari ${ }^{1,2 *}$, Samira Negahdari ${ }^{2}$, Mahnaz Kesmati ${ }^{2}$, Anahita Rezaie ${ }^{3}$ and Gholamreza Shariati ${ }^{4}$
}

\begin{abstract}
Background: Wound healing is often impaired in diabetic animals and humans. Matrix metalloproteases act as proinflammatory agents in physiological wound healing pathways by stimulating cytokines including the interleukins, IL6, ILIA and IL1B, and the tumor necrosis factor and transforming growth factor beta1. Botanicals are traditionally used to assist healing of different types of wounds, because they produce fewer side effects. Our specific aim here was to develop a plant-based recipe supporting effective wound healing in diabetic animals.
\end{abstract}

Methods: Plant materials from Adiantum capillus-veneris, Commiphora molmol, Aloe Vera, and henna were collected for this study, and oven-dried at $60^{\circ} \mathrm{C}$. The dried leaves and resins were then crumbled into a powder and mixed in equal parts with Vaseline as a preservative. This mixture was used as an ointment on wounds induced in 60 diabetic and non-diabetic rats that were divided into 6 subgroups receiving agent or control treatments. Necrotic tissue surrounding the wound was periodically removed during wound healing. RNA was extracted from the healing region of the wound at days 7, 14 and 21 for cDNA synthesis to monitor changes in Tgfb 1, Mmp3, Mmp9, 116 and Tnf a expression using real-time PCR.

Results: The expression of the Mmp3, the Tnf a, and the Tgfb1 genes from wound tissue were significantly different $(p<0.05)$ between diabetic and non-diabetic (control) rats treated with the herbal mixture after 14 and 21 days. There was no significant difference $(p>0.05)$ of the Mmp9 gene expression in diabetic and non-diabetic rats treated only with Vaseline after 7, 14, and 21 days. But, the expression of the Mmp9 gene decreased significantly $(p<0.05)$ in diabetic rats after 14 days in comparison to non-diabetic rats, when the herbal mixture was added to Vaseline.

Conclusions: Our study presents an herbal treatment that alters the gene expression signature at wounds induced in the rat model for type I diabetes in a manner consistent with accelerated healing, and demonstrates that this herbal treatment might be effective to treat wounds in diabetic patients.

Keywords: Wound healing, Diabetic, Matrix metalloproteases, Herbal remedies

\footnotetext{
* Correspondence: galehdari187@yahoo.com

${ }^{1}$ Toxicology Research Center, Ahvaz Jundishapur University of Medical Sciences, Ahvaz, Iran

${ }^{2}$ Department of Genetics, Shahid Chamran University, Ahvaz, Iran

Full list of author information is available at the end of the article
} 


\section{Background}

Wound healing in individuals suffering diabetes requires the coordination of several cellular processes [1]. Incurable wounds in diabetics are mostly linked to postponed cellular penetration, formation of granulation tissue, diminished collagen, reduced blood circulation, increased blood viscosity and reduced angiogenesis [2]. The observation of impaired wound healing in diabetic humans has been mimicked in animal models such as streptozotocin-induced diabetic rats $[3,4]$. The destruction of the extracellular matrix and its modification by matrix metalloproteases is a feature of leukocyte invasion, angiogenesis, re-epithelialization and tissue repair [5-7]. Restricting protease production is crucial to regular wound healing since maintaining high levels of specific matrix metalloproteases can degrade the matrix and compromise repair $[8,9]$. Matrix metalloproteases can also stimulate cytokines and chemokines and promote proinflammatory activity for wound healing. This indicates an association between diabetes-stimulated inflammation and matrix metalloprotease expression [10-12]. Elevated levels of matrix metalloproteases have been reported in hyperglycemic human and mouse models [2, 13]. Many cytokines and growth factors are involved in wound healing. Studies have shown that pro-inflammatory cytokines in human and animal diabetic models, such as interleukins, IL6, IL1A, IL1B, and the tumor necrosis factor (TNF), become elevated immediately after wounding [14-16]. TGFB1 is a multifunctional cytokine and increases formation of granulation tissue and collagen synthesis during wound repair $[17,18]$.

Current wound treatment methods, including wound debridement, irrigation or grafting and wound treatment with antibiotics or proteolytic enzymes can have side effects [19]. However, herbal-based drugs with curative value for various disorders have been described in traditional medicine. Numerous drugs derived from plant resources improve healing of different types of wounds $[20,21]$. Among plants with wound healing capacity, Aloe Vera (Liliaceae) with known anti-fungal, antimicrobial, anti-diabetic, and hypoglycemic properties has been used in traditional medicine as a cathartic or remedy for burns and wounds [22, 23]. Morgan et al. reported that Aloe Vera initiates angiogenesis and wound repair by up-regulating VegfA and the $T g f b l$ expression [24]. Vija Yalakshmi et al. reported that Aloe Vera acts as an anti-inflammatory agent by inhibiting $M M P 9$ expression in peripheral mononuclear blood cells [25]. Studies have indicated that the use of oral or topical Aloe Vera affects phases of inflammation, collagen synthesis, maturation and wound closure to improve wound healing in the diabetic rat model [26-28]. Commiphora molmol (Myrrha) produces resin with anti-bacterial, anti-fungal and anti-diabetic properties [29,30], and is currently used to treat wounds, intestinal disorders, diarrhea, coughs and inflammation [31, 32]. Terpenoids, steroids, flavonoids, sugars and lignums are all present in Commiphora molmol [33]. Lotfy et al. reported that the combined use of honey, bee propolis, and Myrrha promoted wound healing in a patient with diabetes mellitus [34]. Adiantum capillus-veneris also has a long history in traditional medicine and exhibits anti-inflammatory, antidiabetic, anti-infective, anti-microbial, and anti-oxidant properties [35]. Adiantum capillus-veneris has significant angiogenic capacity of wound healing in vitro [36]. These properties suggest that local administration of Adiantum capillus-veneris could have healing capability. Henna (Lawsonia inermis) is a well-known plant that is widely used to treat headaches, boils and skin inflammation. Experimental and clinical studies have demonstrated that Henna has anti-bacterial and anti-fungal properties, and exhibits hypoglycemic and anti-hyperglycemic effects that assist wound healing [37, 38].

Here we investigated whether a combination of the botanicals, Adiantum capillus-vernis, Commiphora molmol, Aloe Vera and Henna, can improve the wound healing effectively in streptozotocin-induced diabetic and non-diabetic rats.

\section{Methods}

\section{Collection and preparation of the herbal mixture}

Fresh Aloe Vera leaves were collected from the botanical garden at Jundishapur Ahvaz University of Medical Sciences and their identity verified by the Department of Horticulture (No.93). Shoots of Adiantum capillusveneris (A. diantaceae) were collected from the Lorestan province in Iran (no. 1661). Fresh henna leaves were collected in the city of Kerman, Iran (KF 1408). The oleo gum resin of Commiphora mol was obtained from Saudi Arabia. The origin of plant materials were systemically identified and approved in the herbarium of Shahid Chamran University of Ahvaz, Iran. After collecting plants, Henna and Aloe Vera fresh leaves and Adiantum capillus-veneris shoots, they were washed and ovendried at $60{ }^{\circ} \mathrm{C}$. The dried leaves and resin of the Myrrha were then crumbled in a blender to create a fine powder that was mixed in equal parts with Vaseline as a preservative.

\section{Animals and treatment groups}

Sixty adult male Wistar rats (200-220 g) were used in this study, which was authorized by the Medical Ethics Committee of Ahvaz Jundishapur University of Medical Sciences.. Rats were housed separately in a temperaturecontrolled $\left(22-24{ }^{\circ} \mathrm{C}\right)$ room on a12 h light/dark cycle, and food and water were provided ad libidum. Type I diabetes mellitus was induce in half the animals used for this study, then diabetic and non-diabetic and diabetic 
animals were further divided into 2 treatment subgroups (Table 1).

\section{Induction of type 1 diabetes mellitus}

After a fasting period of $12 \mathrm{~h}$, diabetes was induced in the test rats by intra-peritoneal injection of $60 \mathrm{mg}$ streptozotocin (Sigma-Aldrich; USA) in saline-sodium citrate buffer per kg body weight. The rats consumed $5 \%$ glucose solution all night to neutralize the hypoglycemia stimulated by the streptozotocin. Seven days after injection of streptozotocin, the blood glucose concentration was measured in the rats using a glucometer. One week post-injection, type 1 diabetes was identified in each rat by a blood glucose level that was consistently above $250 \mathrm{mg} / 100 \mathrm{ml}$. Diabetic rats exhibited typical symptoms of diabetes mellitus including polyuria, polyphagia and weight loss. Blood glucose levels were tested every 3 days in each rat throughout the study duration.

\section{Wound model}

The wound was created on day zero on each rat in each treatment group. Rats were anesthetized by intraperitoneal injection of ketamine $(50 \mathrm{mg} / \mathrm{kg}$ ) and xylazine $(10 \mathrm{mg} / \mathrm{kg})$. The fur on the back of each rat was first shaved off, and the wound site sterilized with $70 \%$ alcohol before the skin wound was created by excising a circular region of skin about $2 \mathrm{~cm}$ in diameter (Fig.1).

\section{Tissue collection and expression analysis}

Rats were euthanized with chloroform on days 7, 14, and 21 post-wounding. The wound and an edge of approximately $2 \mathrm{~mm}$ of adjacent skin were excised. The tissue sample was submerged in RNAlater (Qiagen; Germany) overnight at $4{ }^{\circ} \mathrm{C}$. Total RNA was extracted from the tissues using the RNeasy Fibrous Tissue Mini Kit (Qiagen; Germany) according to manufacturer's instructions, and stored at $-80{ }^{\circ} \mathrm{C}$. The RNA was reverse transcribed using the Quanti Tect Reverse Transcription Kit (Qiagen; Germany) as per instructions. The obtained

Table 1 Each group was classified into two subgroups including only Vaseline treatment and Vaseline plus herbal mixture. It is noted that because Vaseline was used in this study as preservative, we had have to show its putative effect on gene expression in comparison to plant mixture. Each of subgroups contain five rats $(n=5)$. The gene expression was measured in periods of 7, 14, and 21 days after treatment with Vaseline or Vaseline and mixture

\begin{tabular}{|c|c|c|c|c|}
\hline \multirow{2}{*}{$\begin{array}{l}\text { Time } \\
\text { (day) }\end{array}$} & \multicolumn{2}{|c|}{ Group I: non-diabetic } & \multicolumn{2}{|c|}{ Group II: diabetic } \\
\hline & Vaseline & $\begin{array}{l}\text { Herbal mixture } \\
\& \text { Vaseline }\end{array}$ & Vaseline & $\begin{array}{l}\text { Herbal mixture } \\
\text { \& Vaseline }\end{array}$ \\
\hline 7 & 5 rats & 5 rats & 5 rats & 5 rats \\
\hline 14 & 5 rats & 5 rats & 5 rats & 5 rats \\
\hline 21 & 5 rats & 5 rats & 5 rats & 5 rats \\
\hline
\end{tabular}

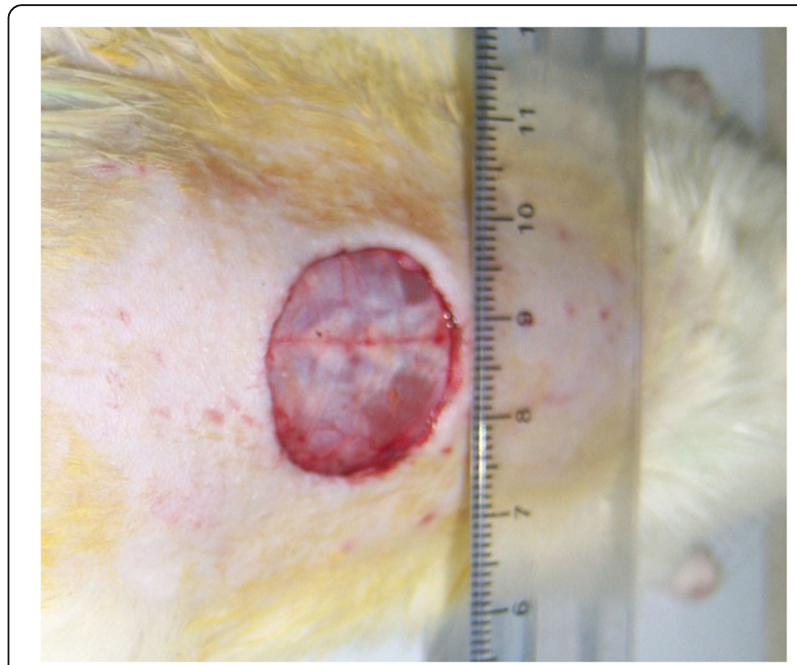

Fig. 1 A 2-cm circular wound traversed both the epidermis and dermis on the back of each test rat at day 0

cDNA was used for real-time PCR with master SYBR Green I (Takara Bio; Japan) on the ABI 7900HT. Realtime PCR was executed at $95{ }^{\circ} \mathrm{C}$ for $10 \mathrm{~s}, 62^{\circ} \mathrm{C}$ for $15 \mathrm{~s}$, and $72{ }^{\circ} \mathrm{C}$ for $8 \mathrm{~s}$ using primers for the normalizing gene, glyceraldehyde 3-phosphate dehydrogenase)Gapdh(and target genes, Mmp3, Mmp9, Tgfb1, Il6, and Tnf. Primers were designed by Gen Script according to the cDNA sequences of rat Mmp3, Mmp9, Tgfb1, Il6, Tnf and Gapdh in Gene Bank (Table 2). Real-time PCR was carried out twice on every cDNA sample. Target gene expression was monitored in wound tissue collected on days 7,14 and 21 from diabetic and non-diabetic rats treated with either the herbal mixture in Vaseline as preservative or Vaseline alone.

RNA isolated from the healing wound samples 7,14 or 21 days after wound induction were reversed transcribed then gene expression analyzed in multiplex real-time PCR assays. Melting curves were obtained for each gene to validate data, and curves confirmed the accuracy of the peak corresponding to the gene of interest and strings of primer dimer. A standard curve was plotted to evaluate reaction efficiency using different dilutions of cDNA before realtime PCR multiplex assay implementation.

\section{Data analysis}

Differences in gene expression were determined between treatment groups using the REST relative expression software tool (version 2009). REST calculates the relative expression of group means for target genes, which in our case were $T g f b 1, M m p 3, M m p 9$, Il6 and $\operatorname{Tnf} \alpha$ normalized for expression of the gapdh housekeeping gene in the treatment and control groups. Results were considered statistically significant when $p$ values $<0.05$. 
Table 2 Sequence of designed primers for each gene is shown as forward and reverse. The primers used here for real time PCR were designed by www.GeneScript.com according their accession number

\begin{tabular}{llll}
\hline Gene & GenBank accession Number & Forward primer (5'-3') & Reverse primer $\left(5^{\prime}-3^{\prime}\right)$ \\
\hline GAPDH & [NM_017008.3] & ATGACTCTACCCACGGCAAG & CTGGAAGATGGTGATGGGTT \\
MMP-9 & {$[$ NM_031055] } & TCGAAGGCGACCTCAAGTG & TTCGGTGTAGCTTGGATCCA \\
MMP3 & [NM_133523] & TCTITCACTCAGCCAATGCT & GGGAGGTCCATAGAGGGATT \\
IL-6 & {$[$ NM_012589.1] } & AGTCCGGAGAGGAGACTTCA & TTGCCATTGCACAACTCTT \\
TNFa & [NM_012675.3] & CCACCACGCTCTTCTGTCTA & GCTTGGTGGTTTGCTACGA \\
TGFB1 & [NM_031131.1] & CTGAACCAAGGAGACGGAAT & GGTTCATGTCATGGATGGTG \\
\hline
\end{tabular}

\section{Results}

We used both visual assessment and gene expression to assess the effect of an herbal mixture on healing of wounds induced in diabetic and non-diabetic rats.

The present investigation determined changes in the expression of the Tgfb1, Mmp3, Mmp9, Il6 and Tnf $\alpha$ genes by real-time-PCR at the day 7 , the day 14 and the day 21 post-wounding in the diabetic and non-diabetic rats. For data validation, melting curves were obtained for each gene. The curves confirm the accuracy of the peak corresponding to the gene of interest and strings of primer dimer. A standard curve was plotted to evaluate the efficiency of the reaction using different dilutions of the synthetic cDNA before implementation of real-time PCR.

However, data showed significant difference $(p<0.05)$ in the expression of the Mmp3, the IL6, Tnf $\alpha$ and $T g f b 1$ genes between diabetic and non-diabetic rats 14 daysays and 21 days after treatment with the herbal mixture at the wound site (Fig. 2). The $M m p 9$ gene expression was firstly decreased at the day 14 and increased again at the 21th day in diabetic rats compared to nondiabetic rats treated with herbal mixture $(p<0.05)$ as has been shown in Fig. 2.
Tgfb1, Mmp3, Il6 and Tnf a expression steadily increased during would healing, as shown by the significant increases between days 7 and 14 and days 14 and 21 in either diabetic or non-diabetic rats treated with the herbal mixture.

The expression of Mmp3 at $14 \mathrm{~d}, I l 6$ at 14 and $21 \mathrm{~d}$, $\operatorname{Tnf} \alpha$ at $21 \mathrm{~d}$ and $T g f b 1$ at 7, 14 and 21 days post-wounding in diabetic rats treated with Vaseline was significantly different $(p<0.05)$ from that of non-diabetic rats (Fig. 3). There was no significant difference $(p>0.05)$ for the $M m p 9$ gene expression in diabetic rats and non-diabetic rats treated with Vaseline at $7 \mathrm{~d}, 14 \mathrm{~d}$, and $21 \mathrm{~d}$ postwounding (Fig. 3).

We couldn't see any significant changes $(p>0.05)$ in the expression of the $M m p 3$, the $I l 6$, the $\operatorname{Tn} f \alpha$, the $M m p 9$ and the $T g f b 1$ in diabetic rats treated with herbal mixture in comparison to diabetic rats treated with Vaseline, as for the non-diabetic rats (Figs. 4 and 5).

\section{Discussion}

Here we introduce a herbal mixture that could assist wound healing in diabetic persons. Observational comparisons of wound healing were coupled with gene expression

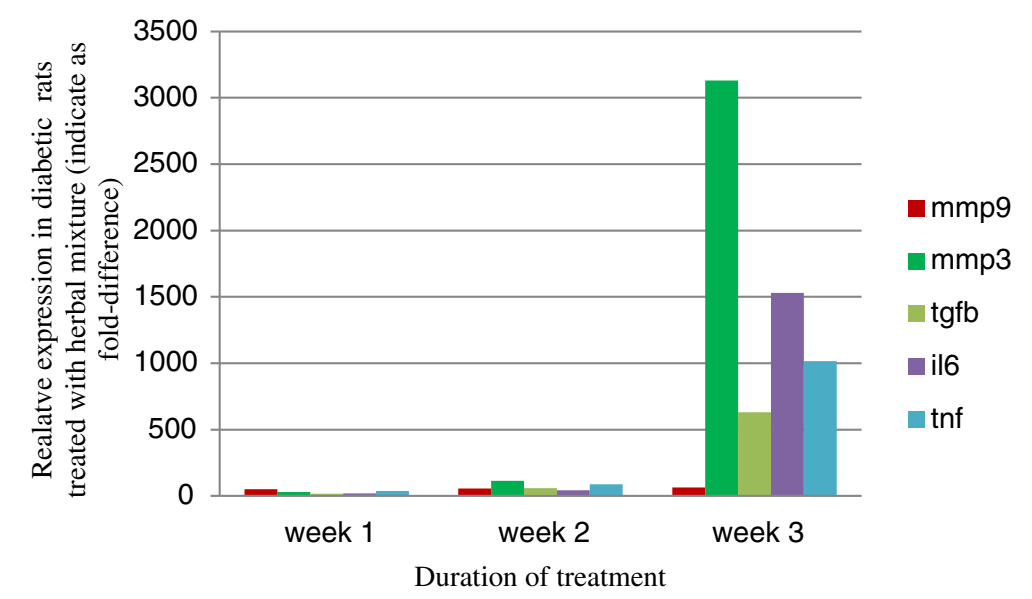

Fig. 2 Fold-difference in gene expression in tissue removed from wounds in diabetic versus control rats treated with herbal mixture at 7,14 and 21 days (indicated as week 1, week 2 and week 3) after treatment. The diagram signifies here the increased expression of mentioned genes in diabetic rats after 3 weeks treatment with herbal mixture 


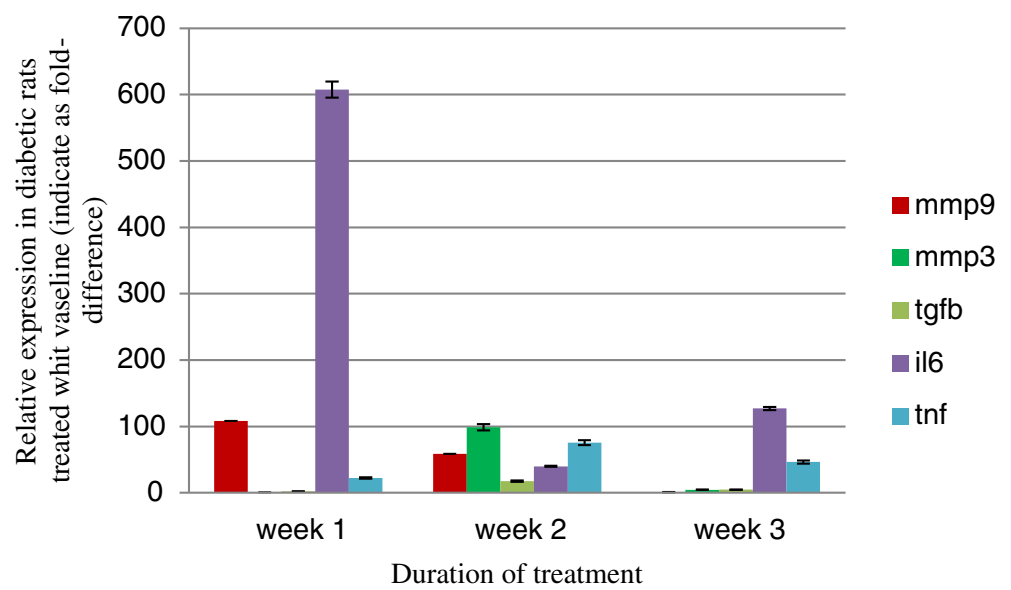

Fig. 3 Fold-difference in gene expression in tissue removed from wounds induced in diabetic versus control rats treated with the Vaseline control at days 7, 14 and 21 of the wound healing process

analysis in wound tissue in a time series during healing, and the herbal mixture was compared with control treatment in the type I diabetic compared with control rat subgroups. Physical observation and expression data demonstrate that our herbal formula significantly increases $M m p 3, T g f b 1$ and $\operatorname{Tnf} \alpha$ expression in the healing wound over time compared to control treatment with Vaseline. Keratinocytes at a wound site express MMP3 (formerly known as stromelysin 1), which is essential for reepithelialization and tissue remodeling $[2,39]$. MMP3 acts proteolytically on the substrates, fibronectin, laminin, vitronectin, collagens and pro-MMP9, for extracellular matrix remodeling [40, 41]. MMP3 was proposed to be necessary for wound closure, since the rate of wound healing was reported to be reduced in Mmp3-deficient mice. The stringing of the MMP3 or the addition of a synthetic inhibitor of the MMP family decelerates wound contraction [42]. MMP3 enhanced endothelial cell proliferation and migration in vitro as well as inhibiting apoptosis in these cells, suggesting that MMP3 is an indirect regulator of angiogenesis [5]. Here we showed that herbal mixture treatment up-regulated $M m p 3$ expression in the diabetic rats compared with non-diabetic rats during the later phase of wound healing. Thus, the ingredients in the herbal mixture are capable of increasing $M m p 3$ expression in diabetic rats, which supports a positive effect on extracellular matrix remodeling in the wound even within a diabetic physiological background.

Keratinocyte migration is dependent on MMP9 (formerly known as gelatinase B). In cells with a high glucose concentration, MMP9 expression has been shown to be evaluated in a similar way as has previously been observed in diabetic wounds [11, 43]. Kowluru et al. demonstrated that MMP9 activation under hyperglycemic conditions might activate apoptosis through the caspase 3 pathway [43]. MMP9 accelerates healing of otherwise

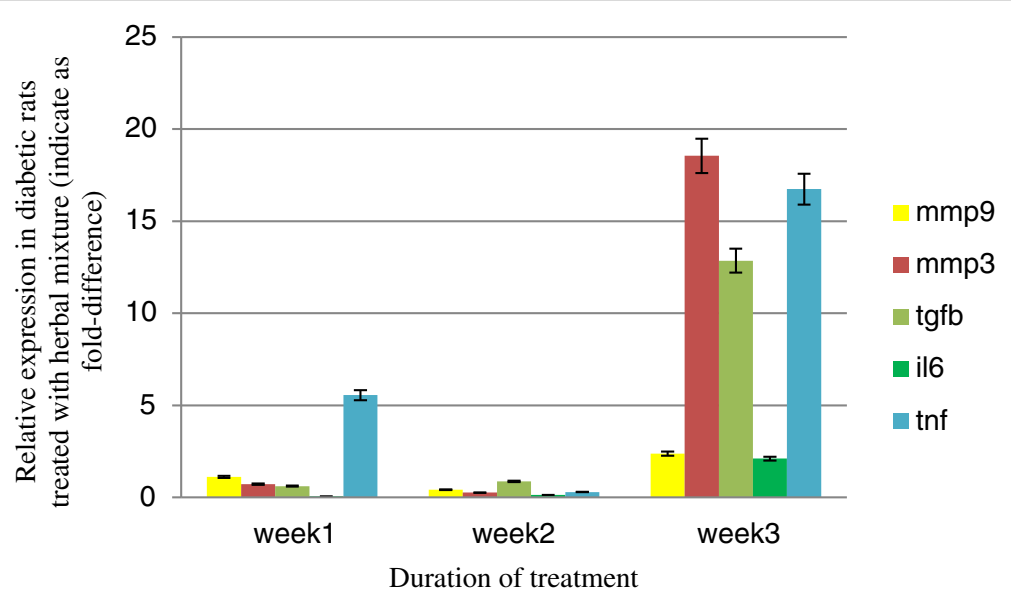

Fig. 4 Fold-difference in gene expression in tissue removed from wounds induced in diabetic rats treated with the herbal mixture compared to the Vaseline control at days 7, 14 and 21 of the wound healing process 


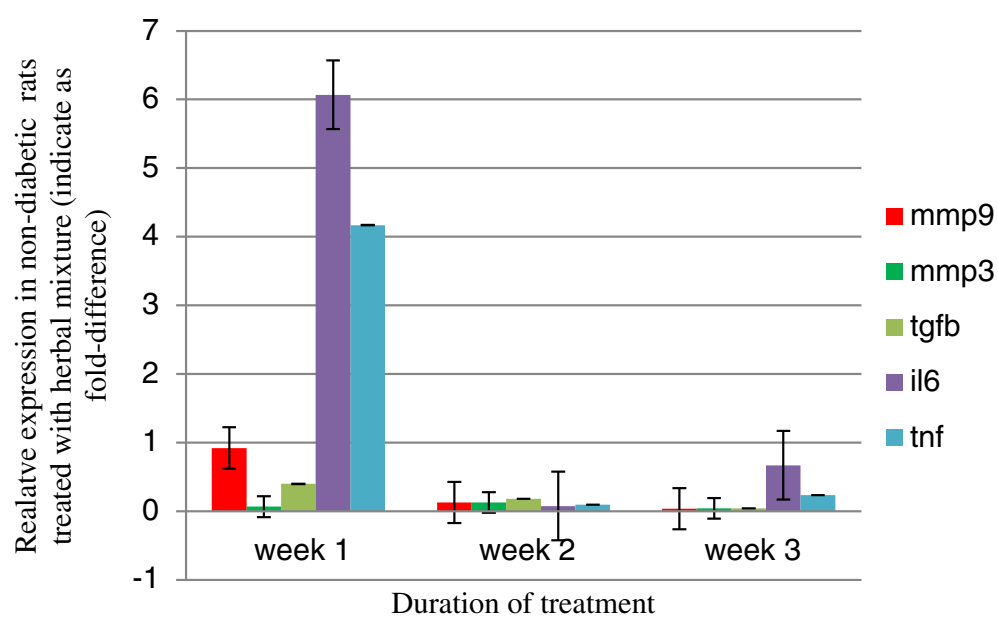

Fig. 5 Fold-difference in gene expression in tissue removed from wounds induced in non-diabetic rats treated with the herbal mixture compared with the Vaseline control at days 7, 14 and 21 of the wound healing process

poorly healing wounds in diabetic individuals, and is implicated in a number of pro-inflammatory events that can induce cytokine activity and potentiate inflammatory response [44]. The mechanism leading to the Mmp9 up-regulation is poorly understood, but has been associated with increased inflammation. Neutrophils and macrophages permeate the wound during the inflammatory phase, then proceed to phagocytose bacteria and increase $M m p 9$ expression [45, 46]. Mmp9 upregulation is coordinated by inflammatory cytokines including TNF, IL1B, IL6 and growth factors [43, 47, 48]. However, we did not observe any significant differences in Mmp9 expression at the wound site in diabetic or non-diabetic rats treated with herbal mixture during the 3-week period examined.

Macrophages, $\mathrm{T}$ cells, fibroblasts, keratinocytes and endothelial cells can all produce IL6, and contribute particularly to the early inflammatory phase of wound repair $[49,50]$. IL6 may regulate leukocyte recruitment to inflammatory sites and fibrotic changes [49]. Wound healing has been demonstrated to also occur in Il6-deficient mice [51]. Studies have shown that Il6 is significantly upregulated in kidney tissue of diabetic rats [52] and humans [53]. In the present study, Il6 expression was elevated at day 14 in wound samples from diabetic rats in comparison to non-diabetic rats both treated with the herbal mixture.

TNF is produced by leukocytes and macrophages, whose activation causes acute inflammation via cleavage of TNF from the cell membrane $[54,55]$. TNF acts on inflammatory cells, such as monocytes, and is stimulated by higher amount of $M M P 9$ expression though the activation of the NF-kappa B complex and MAPK signaling [56]. Deactivating TNF signaling in diabetic wounds escalates angiogenesis and wound closure [57]. Apoptosis of fibroblasts in diabetic mice is considerably higher than in non-diabetic mice. Otherwise, TNF appears to induce apoptosis in fibroblasts, keratinocytes and endothelial cells in vitro $[58,59]$. The migration of fibroblasts and keratinocytes is delayed in diabetics [60]. High TNF levels restrain cell migration. This may occur through elevating SMAD7 levels in the cells, thus, inhibiting signaling activation through SMAD2/3 [57]. In the current study, Tnf expression was elevated in wound tissue sampled on days 14 and 21 in diabetic compared with nondiabetic rats all treated with the herbal mixture.

TGFB1 is a multifunctional cytokine released in abundance from platelets, and promotes macrophages, fibroblasts and neutrophils to produce more TGFB1 $[16,61]$. TGFB1 is a key mediator implicated in the differentiation and migration of fibroblasts and endothelial cells. Fibroblast migration and proliferation are thought to be important features of wound healing, as fibroblasts are responsible for synthesizing new extracellular matrix proteins, primarily type I and type III collagens [62, 63]. Interestingly, non-healing wounds often show a loss of the TGFB1 signaling $[16,64]$. Here we show that $T g f b 1$ expression is significantly up-regulated in wound tissue sampled on days 14 and 21 from diabetic rats in comparison to non-diabetic rats all treated with the herbal mixture.

The herbal mixture introduced in this study has not been previously investigated for its effect on wound healing in diabetic rats. However, research on single components, namely Commiphora molmol, revealed that the terpenoids (especially furanose squiterpenes) are the active compounds present in myrrh essential oil [33, 65]. Phenolic compounds, alkaloids and saponins have also been detected in extracts of Commiphora molmol. Manjula et al. demonstrated in vitro that Commiphora molmol resin has anti-inflammatory properties, which occur via inhibition 
of interferon gamma (IFNG), IL-12, TNF, IL1B, and nitric oxide levels [66]. The second component in our mixture is Aloe Vera, which possesses substantial amounts of phenol, saponins and anthraquinones, known to be responsible for anti-bacterial, anti-viral and anti-fungal activity [67]. Acemannan is a major carbohydrate fraction obtained from Aloe Vera leaves, which produces anti-viral and anticancer effects and stimulates the immune system and macrophages [68, 69]. Jettanacheawchankit et al. investigated the effects of Acemannan on the production of keratinocyte growth factor-1 (KGF1),VEGF and type I collagen, and reported that Acemannan is important for oral wound healing [70]. A histological study has revealed that Aloe vera enhances wound vascularity, which assists dead tissue removal and increases wound health. The ascorbic acid in Aloe vera boosts collagen synthesis to counterbalance collagen breakdown. Collagen is the main extracellular protein involved in granulation tissue homeostasis in a healing wound [1]. Morgan et al. stated that Aloe Vera enhances angiogenesis and wound repair through upregulating Vegf and Tgfb1 expression [24]. Vijayalakshmi et al. reported that Aloe Vera acts as an anti-inflammatory agent by inhibiting the effect of Mmp9 on peripheral blood mononuclear cells [25]. Abita et al. reported that oral administration of Aloe Vera improved wound healing and increased the expression of $V e g f$ and $T g f b l$ in type 2 diabetic rats [26]. The leaves of the henna plant contain phytochemical ingredients such as tannin, gallic acid, glucose, mannitol, fat, resin, flavonoids, coumarins and anthraquinones [71, 72]. Habbal et al. showed that henna leaf extracts are efficient in preventing infections by inhibiting the growth of microorganisms [73]. Nilforoushzadeh et al. evaluated the effects of Adiantum capillus-veneris on wound healing, and reported that this plant promoted angiogenic effects and proliferation of endothelial cells in vitro [36]. The antioxidant activity of Adiantum capillus-veneris could be the result of polyphenolic and flavonoid activity [74]. Flavonoids are recognized for their antioxidant, anti-inflammatory, and cell protective properties $[75,76]$.

\section{Conclusions}

The present study demonstrated that the prescribed herbal mixture is effective for wound healing and improves conditions at the wound site to promote better closure and healing.

\section{Abbreviations \\ ECM: Extracellular matrix; GAPDH: Glyceraldehyde 3-phosphate dehydrogenase; IL-6: Interleukin-6; MMPs: Matrix metalloproteases; PCR: Polymerase chain reaction; TGF $\beta 1$ : Transforming growth factor beta1; TNFa: Tumor necrosis factor a}

\section{Acknowledgements}

This study was supported by the toxicology research center of Ahvaz Jundishapur University of Medical Sciences, Ahvaz, Iran. The authors wish to thank Narges Laboratory and Biology Department of Shahid Chamran University for technical assistance.

\section{Funding}

There is no Funding for this study.

Availability of data and materials

Data are all contained within the paper and are also available from the corresponding author on reasonable request.

\section{Authors' contributions}

All authors had equal role in design, work, statistical analysis and manuscript writing. All authors read and approved the final manuscript.

\section{Competing interests}

The authors declare that they have no competing interests.

\section{Consent for publication}

Not Applicable.

\section{Ethics approval and consent to participate}

The Medical Research Ethics Committee of Jundishapur University of Ahvaz approved this project with the number TRC-9204.

\section{Author details}

${ }^{1}$ Toxicology Research Center, Ahvaz Jundishapur University of Medical Sciences, Ahvaz, Iran. 'Department of Genetics, Shahid Chamran University, Ahvaz, Iran. ${ }^{3}$ Department of Pathobiology, Faculty of Veterinary Medicine, Shahid Chamran University of Ahvaz, Ahvaz, Iran. ${ }^{4}$ Department of Medical Genetics, Faculty of Medicine, Jundishapur University of Medical Sciences, Ahvaz, Iran.

Received: 7 February 2016 Accepted: 9 September 2016

Published online: 06 October 2016

\section{References}

1. Chithra P, Sajithlal GB, Chandrakasan G. Influence of aloe vera on the healing of dermal wounds in diabetic rats. J Ethnopharmacol. 1998:59(3):195-201.

2. Babaei S, Bayat M, Nouruzian M. Pentoxifylline improves cutaneous wound healing in streptozotocin-induced diabetic rats. Eur J Pharmacol. 2012;700(1-3):165-72.

3. Blakytny $R$, Jude $E$. The molecular biology of chronic wounds and delayed healing in diabetes. Diabet Med. 2006;23(6):594-608.

4. Darby IA, et al. Apoptosis is increased in a model of diabetes-impaired wound healing in genetically diabetic mice. Int J Biochem Cell Biol. 1997:29(1):191-200.

5. Zheng $L$, et al. Matrix metalloproteinase-3 accelerates wound healing following dental pulp injury. Am J Pathol. 2009;175(5):1905-14.

6. Ravanti L, Kahari VM. Matrix metalloproteinases in wound repair (review). Int J Mol Med. 2000;6(4):391-407.

7. Galko MJ, Krasnow MA. Cellular and genetic analysis of wound healing in Drosophila larvae. PLoS Biol. 2004;2(8):E239.

8. Frankwich $\mathrm{K}$, et al. Proof of Concept: Matrix metalloproteinase inhibitor decreases inflammation and improves muscle insulin sensitivity in people with type 2 diabetes. J Inflamm (Lond). 2012;9(1):35.

9. Gutierrez-Fernandez A, et al. Increased inflammation delays wound healing in mice deficient in collagenase-2 (MMP-8). FASEB J. 2007;21(10):2580-91.

10. Rodrigues SF, et al. Matrix metalloproteinases cleave the beta2-adrenergic receptor in spontaneously hypertensive rats. Am J Physiol Heart Circ Physiol. 2010;299(1):H25-35

11. McLennan SV, Martell SY, Yue DK. High glucose concentration inhibits the expression of membrane type metalloproteinase by mesangial cells: possible role in mesangium accumulation. Diabetologia. 2000;43(5):642-8.

12. McLennan SV, et al. High glucose concentration causes a decrease in mesangium degradation. A factor in the pathogenesis of diabetic nephropathy. Diabetes. 1994;43(8):1041-5.

13. Lobmann $\mathrm{R}$, et al. Expression of matrix-metalloproteinases and their inhibitors in the wounds of diabetic and non-diabetic patients. Diabetologia. 2002;45(7):1011-6. 
14. Barrientos $S$, et al. Growth factors and cytokines in wound healing. Wound Repair Regen. 2008;16(5):585-601.

15. Badr G, et al. Treatment of diabetic mice with undenatured whey protein accelerates the wound healing process by enhancing the expression of MIP-1alpha, MIP-2, KC, CX3CL1 and TGF-beta in wounded tissue. BMC Immunol. 2012;13:32

16. Werner $S$, Grose R. Regulation of wound healing by growth factors and cytokines. Physiol Rev. 2003;83(3):835-70.

17. Penn JW, Grobbelaar AO, Rolfe KJ. The role of the TGF-beta family in wound healing, burns and scarring: a review. Int J Burns Trauma. 2012;2(1):18-28.

18. Pastar I, et al. Attenuation of the transforming growth factor beta-signaling pathway in chronic venous ulcers. Mol Med. 2010;16(3-4):92-101.

19. Brem H, Tomic-Canic M. Cellular and molecular basis of wound healing in diabetes. J Clin Invest. 2007;117(5):1219-22.

20. Hosein Farzaei $M$, et al. A comprehensive review of plants and their active constituents with wound healing activity in traditional Iranian medicine. Wounds. 2014;26(7):197-206.

21. Prasad V, Dorle AK. Evaluation of ghee based formulation for wound healing activity. J Ethnopharmacol. 2006;107(1):38-47.

22. Atiba A, Ueno $H$, Uzuka $Y$. The effect of aloe vera oral administration on cutaneous wound healing in type 2 diabetic rats. J Vet Med Sci. 2011;73(5):583-9.

23. Ajabnoor MA. Effect of aloes on blood glucose levels in normal and alloxan diabetic mice. J Ethnopharmacol. 1990;28(2):215-20.

24. Morgan C, Nigam Y. Naturally derived factors and their role in the promotion of angiogenesis for the healing of chronic wounds. Angiogenesis. 2013;16(3):493-502.

25. Vijayalakshmi $D$, et al. In vitro anti inflammatory activity of Aloe vera by down regulation of MMP-9 in peripheral blood mononuclear cells. J Ethnopharmacol. 2012;141(1):542-6.

26. Atiba A, Ueno $H$, Uzuka $Y$. The effect of aloe vera oral administration on cutaneous wound healing in type 2 diabetic rats. J Vet Med Sci. 2010;73(5):583-9.

27. Chithra P, Sajithlal GB, Chandrakasan G. Influence of Aloe vera on collagen characteristics in healing dermal wounds in rats. Mol Cell Biochem. 1998;181(1-2):71-6.

28. Rajasekaran S, Sivagnanam K, Subramanian S. Antioxidant effect of Aloe vera gel extract in streptozotocin-induced diabetes in rats. Pharmacol Rep. 2005;57(1):90-6.

29. Nomicos EY. Myrrh: medical marvel or myth of the Magi? Holist Nurs Pract. 2007;21(6):308-23.

30. Massoud A, El Sisi S, Salama O. Preliminary study of therapeutic efficacy of a new fasciolicidal drug derived from Commiphora molmol (myrrh). Am J Trop Med Hyg. 2001;65(2):96-9.

31. Fraternale $\mathrm{D}$, et al. Anti-inflammatory, antioxidant and antifungal furanosesquiterpenoids isolated from Commiphora erythraea (Ehrenb.) Engl. resin. Fitoterapia. 2011:82(4):654-61.

32. Abdul-Ghani RA, Loutfy N, Hassan A. Myrrh and trematodoses in Egypt: an overview of safety, efficacy and effectiveness profiles. Parasitol Int. 2009;58(3):210-4.

33. Tonkal AM, Morsy TA. An update review on Commiphora molmol and related species. J Egypt Soc Parasitol. 2008;38(3):763-96.

34. Lotfy $\mathrm{M}$, et al. Combined use of honey, bee propolis and myrrh in healing a deep, infected wound in a patient with diabetes mellitus. Br J Biomed Sci. 2006;63(4):171-3.

35. Ishaq MS, et al. In vitro phytochemical, antibacterial, and antifungal activities of leaf, stem, and root extracts of Adiantum capillus veneris. Sci World J. 2014;2014:269793.

36. Nilforoushzadeh MA, et al. The Effects of Adiantum capillus-veneris on Wound Healing: An Experimental In Vitro Evaluation. Int J Prev Med. 2014;5(10):1261-8.

37. Nayak BS, et al. The evidence based wound healing activity of Lawsonia inermis Linn. Phytother Res. 2007;21(9):827-31.

38. Mikhaeil BR, et al. Antioxidant and immunomodulatory constituents of henna leaves. Z Naturforsch C. 2004;59(7-8):468-76.

39. Sternlicht MD, Bissell MJ, Werb Z. The matrix metalloproteinase stromelysin-1 acts as a natural mammary tumor promoter. Oncogene. 2000;19(8):1102-13.

40. Cohen M, Meisser A, Bischof P. Metalloproteinases and human placental invasiveness. Placenta. 2006;27(8):783-93.

41. Sautter NB, et al. Tissue remodeling in the acute otitis media mouse model. Int J Pediatr Otorhinolaryngol. 2011;75(11):1368-71.
42. Bullard KM, et al. Impaired wound contraction in stromelysin-1-deficient mice. Ann Surg. 1999:230(2):260-5.

43. Kowluru RA. Role of matrix metalloproteinase-9 in the development of diabetic retinopathy and its regulation by H-Ras. Invest Ophthalmol Vis Sci. 2010;51(8):4320-6.

44. Min D, et al. Activation of macrophage promatrix metalloproteinase-9 by lipopolysaccharide-associated proteinases. J Immunol. 2002;168(5):2449-55.

45. Liu $Y$, et al. Increased matrix metalloproteinase-9 predicts poor wound healing in diabetic foot ulcers. Diabetes Care. 2009;32(1):117-9.

46. Falanga $\mathrm{V}$. Wound healing and its impairment in the diabetic foot. Lancet 2005;366(9498):1736-43.

47. Lockwood CJ, et al. Matrix metalloproteinase 9 (MMP9) expression in preeclamptic decidua and MMP9 induction by tumor necrosis factor alpha and interleukin 1 beta in human first trimester decidual cells. Biol Reprod. 2008;78(6):1064-72.

48. Van den Steen PE, et al. Biochemistry and molecular biology of gelatinase B or matrix metalloproteinase-9 (MMP-9). Crit Rev Biochem Mol Biol. 2002; 37(6):375-536

49. Lin ZQ, et al. Essential involvement of IL-6 in the skin wound-healing process as evidenced by delayed wound healing in IL-6-deficient mice. $J$ Leukoc Biol. 2003;73(6):713-21.

50. Erta M, Quintana A, Hidalgo J. Interleukin-6, a major cytokine in the central nervous system. Int J Biol Sci. 2012;8(9):1254-66.

51. Gallucci RM, et al. Impaired cutaneous wound healing in interleukin-6deficient and immunosuppressed mice. FASEB J. 2000;14(15):2525-31.

52. Navarro-Gonzalez JF, Mora-Fernandez C. The role of inflammatory cytokines in diabetic nephropathy. J Am Soc Nephrol. 2008;19(3):433-42.

53. Agrawal NK, Kant S. Targeting inflammation in diabetes: Newer therapeutic options. World J Diabetes. 2014;5(5):697-710.

54. Gill SE, Parks WC. Metalloproteinases and their inhibitors: regulators of wound healing. Int J Biochem Cell Biol. 2008;40(6-7):1334-47

55. Zhou $\mathrm{M}$, et al. Interferon-gamma differentially regulates monocyte matrix metalloproteinase- 1 and -9 through tumor necrosis factor-alpha and caspase 8. J Biol Chem. 2003:278(46):45406-13.

56. Nguyen J, et al. Protein tyrosine kinase and p38 MAP kinase pathways are involved in stimulation of matrix metalloproteinase-9 by TNF-alpha in human monocytes. Immunol Lett. 2006;106(1):34-41.

57. Xu F, Zhang C, Graves DT. Abnormal cell responses and role of TNF-alpha in impaired diabetic wound healing. Biomed Res Int. 2013;2013:754802.

58. Werner S, Krieg T, Smola H. Keratinocyte-fibroblast interactions in wound healing. J Invest Dermatol. 2007;127(5):998-1008.

59. Liu $\mathrm{R}$, et al. Tumor necrosis factor-alpha mediates diabetes-enhanced apoptosis of matrix-producing cells and impairs diabetic healing. Am J Pathol. 2006;168(3):757-64.

60. Lamers ML, et al. High glucose-mediated oxidative stress impairs cell migration. PLoS One. 2011;6(8):e22865.

61. Assoian RK, et al. Transforming growth factor-beta in human platelets. Identification of a major storage site, purification, and characterization. J Biol Chem. 1983:258(11):7155-60.

62. Wu XB, et al. The effects of Polygonum cuspidatum extract on wound healing in rats. J Ethnopharmacol. 2012;141(3):934-7.

63. Wang XJ, et al. Role of TGF beta-mediated inflammation in cutaneous wound healing. J Investig Dermatol Symp Proc. 2006;11(1):112-7.

64. Brown $\mathrm{RL}$, et al. Wound healing in the transforming growth factor-beta-deficient mouse. Wound Repair Regen. 1995:3(1):25-36.

65. Dolara P, et al. Local anaesthetic, antibacterial and antifungal properties of sesquiterpenes from myrrh. Planta Med. 2000;66(4):356-8.

66. Manjula N, et al. Inhibition of MAP kinases by crude extract and pure compound isolated from Commiphora mukul leads to down regulation of TNF-alpha, IL-1 beta and IL-2. Int Immunopharmacol. 2006;6(2):122-32.

67. Choi SW, et al. The wound-healing effect of a glycoprotein fraction isolated from aloe vera. Br J Dermatol. 2001:145(4):535-45.

68. Zhang L, Tizard IR. Activation of a mouse macrophage cell line by acemannan: the major carbohydrate fraction from Aloe vera gel. Immunopharmacology. 1996;35(2):119-28.

69. Tanaka $M$, et al. Identification of five phytosterols from Aloe vera gel as anti-diabetic compounds. Biol Pharm Bull. 2006;29(7):1418-22.

70. Jettanacheawchankit $\mathrm{S}$, et al. Acemannan stimulates gingival fibroblast proliferation; expressions of keratinocyte growth factor-1, vascular endothelial growth factor, and type I collagen; and wound healing. J Pharmacol Sci. 2009;109(4):525-31. 
71. Kirkland D, Marzin D. An assessment of the genotoxicity of 2-hydroxy-1,4naphthoquinone, the natural dye ingredient of Henna. Mutat Res. 2003;537(2):183-99.

72. Jeyaseelan $\mathrm{EC}$, et al. Antibacterial activity of sequentially extracted organic solvent extracts of fruits, flowers and leaves of Lawsonia inermis $L$. from Jaffna. Asian Pac J Trop Biomed. 2012;2(10):798-802.

73. Habbal $\mathrm{O}$, et al. Antibacterial activity of Lawsonia inermis Linn (Henna) against Pseudomonas aeruginosa. Asian Pac J Trop Biomed. 2011;1 (3):173-6.

74. Askari $\mathrm{G}$, et al. The effect of quercetin supplementation on selected markers of inflammation and oxidative stress. J Res Med Sci. 2012;17(7):637-41.

75. Calderon-Montano JM, et al. A review on the dietary flavonoid kaempferol. Mini Rev Med Chem. 2011;11(4):298-344.

76. Ibraheim ZZ, Ahmed AS, Gouda YG. Phytochemical and biological studies of Adiantum capillus-veneris L. Saudi Pharm J. 2011;19(2):65-74.

Submit your next manuscript to BioMed Central and we will help you at every step:

- We accept pre-submission inquiries

- Our selector tool helps you to find the most relevant journal

- We provide round the clock customer support

- Convenient online submission

- Thorough peer review

- Inclusion in PubMed and all major indexing services

- Maximum visibility for your research

Submit your manuscript at www.biomedcentral.com/submit
Biomed Central 